\title{
Rancang Bangun Band Pass Filter Frekuensi 1.27 GHz untuk Teknologi Synthetic Aperture Radar
}

\author{
RIFAN FITRIANTO ${ }^{1}$, YUYUN SITI ROHMAH ${ }^{2}$, EFA MAYDHONA SAPUTRA ${ }^{3}$
}

\author{
1,2. Universitas Telkom \\ 3. Institut Teknologi Sumatera \\ Email: Rivand2503@gmail.com
}

\begin{abstract}
ABSTRAK
Synthetic Apertur Radar (SAR) adalah teknologi radar yang digunakan untuk pengambilan gambar suatu objek dalam bentuk 2 atau 3 dimensi (penginderaan jarak jauh). Sistem tersebut bekerja pada rentang frekuensi 1.265 sampai dengan 1.275 GHZ dengan frekuensi tengahnya 1.27 GHz. Agar sistem SAR ini dapat bekerja dengan optimal, dibutuhkan suatu perangkat filter yang dapat meloloskan frekuensi yang diinginkan. Sebelumnya sudah ada penelitian yang membuat perangkat ini di band frekuensi yang sama namun menggunakan bahan duroid 5880 dan resonator berbentuk kotak. Bandpass filter Pada penelitian ini dirancang dengan menggunakan metode Hairpin line dan bahan epoxy FR4. Hasil pengukuran menunjukkan nilai Return Loss masih cukup besar yaitu -9.33 dB dan nilai Insertion Loss minimal sebesar -13.51 dB.
\end{abstract}

Kata kunci: Syntethic Aperture Radar, Band Pass Filter, Hairpin-line

\begin{abstract}
Synthetic Aperture Radar (SAR) is a radar technology that used for taking an object in the form of 2 or 3 dimensions (remote sensing). It works in the frequency range 1.265 to $1.275 \mathrm{GHZ}$ with a middle frequency of $1.27 \mathrm{GHz}$. SAR system can work optimally if it support a filter device that can pass the desired frequency. Previously there has been research that makes this device in the same frequency band but using 5885 duroid material and square resonator. Bandpass filter In this study designed using Hairpin line method and FR4 epoxy material. The measurement results of Return Loss values are still quite large arround $9.33 d B$ and Insertion Loss minimum at $-13.51 d B$.
\end{abstract}

Keywords: Syntethic Aperture Radar, Band Pass Filter, Hairpin line 


\section{PENDAHULUAN}

Synthetic Aperture Radar (SAR) merupakan suatu teknologi sistem radar yang aplikasinya digunakan untuk penginderaan permukaan bumi (remote sensing). Sistem SAR ini bekerja pada frekuensi $1265-1275 \mathrm{MHz}$ dengan frekuensi tengah $1270 \mathrm{MHz}$. Perangkat sistem ini tidak lepas dari pengaruh noise dan interferensi. Oleh karena itu agar sistem SAR dapat bekerja dengan baik maka dibutuhkan band pass filter (BPF) untuk bisa meloloskan frekuensi yang diinginkan. Filter yang baik harus memiliki tingkat akurasi slope yang tajam untuk mengurangi derau pada frekuensi tersebut yang bisa mengganggu kinerja sensor SAR. Beberapa penelitian sebelumnya (T.Jayanthy, 2011) merancang suatu BPF Haipin menggunakan Struktur Defected Ground dan metode stub terbuka. (Jiejin Wu, 2008) mendesain transisi Band Pass Filter pada frekuensi Ka Band dari bentuk waveguide menjadi mikrostrip, (Zalabsky, 2013) membuat suatu microwave filter pada range $S$ band untuk aplikasi Radar, (Edwar, 2016) merancang suatu band pass filter mikrostrip yang terbuat dari square loop resonator untuk radar cuaca pada frekuensi $x$-band. (Budi Syihabuddin, 2017) merancang BPF untuk aplikasi radar frekuensi $L$-band dengan menggunakan bahan duroid 5880 dan resonator kotak. Selain itu penelitian lain tentang simulasi pada perancangan filter analog dengan respon chebychev (Rustamaji, 2013).

Pada penelitian ini merancang dan merealisasikan suatu Band Pass Filter pada Synthetic Aperture Radar (SAR) dengan Frekuensi $1.27 \mathrm{GHz}$ dengan menggunakan metode Hairpin dan substrat epoxy FR4. Pada bagian transmitter, Band pass filter digunakan untuk mengurangi noise dan menghilangkan sinyal harmonik yang dihasilkan oleh mixer dan juga untuk meloloskan sinyal frekuensi RF yang dihasilkan oleh up-converter pada range frekuensi 1265$1275 \mathrm{MHz}$ dan $1.27 \mathrm{GHz}$ sebagai frekuensi tengahnya. Kemudian di receiver, filter ini berfungsi untuk memperkuat sinyal yang diterima dan meloloskan sinyal tersebut dengan memberikan perbedaan maksimum antara echo yang diinginkan dan interferensi yang tidak diinginkan. Tujuan dari penelitian ini adalah menghasilkan prototype bandpass filter sederhana yang dapat bekerja pada frekuensi $1.27 \mathrm{GHz}$ dengan nilai return loss dan insertion loss yang kecil sehingga filter tersebut dapat diaplikasikan di sistem SAR.

\section{Filter}

Filter merupakan rangkaian yang meloloskan suatu band frekuensi tertentu yang diinginkan dan meredam band frekuensi lainnya (Sulaeman, Darlis, \& Dewi, 2013). Filter dapat dibagi berdasarkan daerah passband dan stopband nya. Berdasarkan daerah passband dan stopband nya filter dapat dibagi menjadi 4, yaitu:LPF, HPF, BPF dan BSF.

\section{Respon Frekuensi pada Filter (Pozar, 1998)}

Ada dua spesifikasi perbandingan rugi-rugi daya (Power Loss Ratio/PLR) yang sangat berguna pada perancangan filter frekuensi tinggi, yaitu PLR yang memiliki respon frekuensi yang rata pada daerah passband nya yang dikenal dengan Maximally Flat atau respon Butterworth dan yang kedua adalah respon passband mempunyai ripple yang sama (equal ripple) yang terdiri dari respon Chebyshev dan Elliptic.

\section{Prototipe Lowpass Filter Chebyshev (Lancaster, 2001)}

Pada respon Chebyshev, bentuk respon frekuensi tergantung dari jumlah elemen atau orde filter. Semakin banyak jumlah elemen filter, maka bentuk respon antara daerah passband dan stopband semakin curam dan sebaliknya apabila jumlah elemen sedikit, bentuk respon menjadi landai. 
Kemudian untuk mencari nilai setiap elemen yang digunakan pada prototype Chebyshev dapat menggunakan persamaan berikut:

$$
\begin{aligned}
& \mathrm{g}_{0}=1.0 \\
& \mathrm{~g}_{1}=\frac{2}{\gamma} \sin \left(\frac{\pi}{2 \mathrm{n}}\right) \\
& \mathrm{g}_{i}=\frac{1}{\mathrm{~g}_{i-1}} \frac{4 \sin \left[\frac{\left(2_{i}-1\right) \pi}{2 n}\right] \sin \left[\frac{2_{i}-3}{2 n}\right]}{\gamma^{2}+\sin ^{2}\left[\frac{i-1}{n}\right]}
\end{aligned}
$$

untuk $i=2,3, \ldots \mathrm{n}$

dengan :

$$
\begin{aligned}
& \gamma=\sinh \left(\frac{\beta}{2 n}\right) \\
& \beta=\ln \left[\operatorname{coth}\left(\frac{L_{A r}}{17.73}\right)\right.
\end{aligned}
$$

Keterangan :

$$
\begin{aligned}
& \mathrm{n} \text { : urutan elemen ke- } \\
& \text { LAr : nilai ripple yang ditentukan }
\end{aligned}
$$

\section{Inverter (Lancaster, 2001)}

Untuk merealisasikan sebuah rangkaian filter pada saluran mikrostrip dibutuhkan suatu inverter untuk mengubah rangkaian menjadi jalur mikrostrip. Terdapat dua jenis inverter yang biasa digunakan pada rangkaian filter mikrostrip, yaitu $K$-Inverter dan J-Inverter. $K$-Inverter digunakan untuk mengubah rangkaian filter menjadi rangkaian yang terdiri dari rangkaian induktor seri. Sedangkan J-Inverter digunakan untuk mengubah rangkaian filter menjadi rangkaian yang terdiri dari kapasitor paralel.
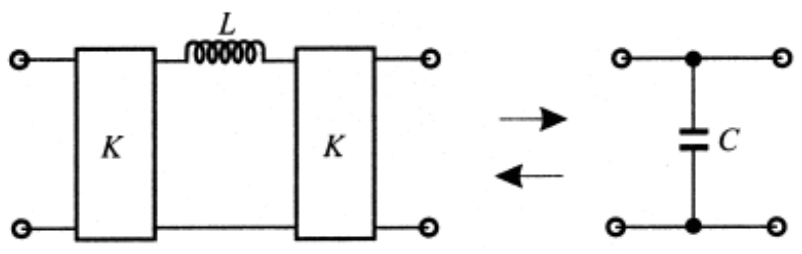

(a)
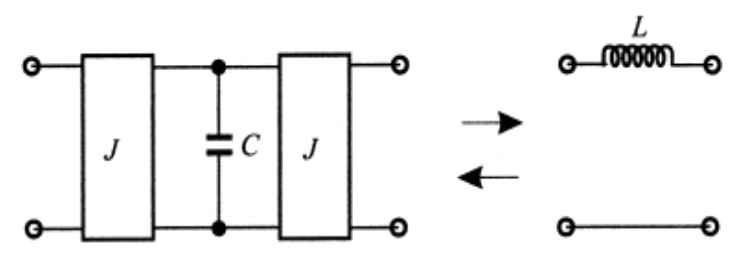

(b)

Gambar 1. (a) Rangkaian K-Inverter (b) Rangkaian J-Inverter 
Inverter ideal adalah transformator seperempat panjang gelombang. Impedansi dan admitansi pada satu ujung transformator akan diubah ke impedansi dan admitansi ujung yang lain, sebanding dengan kuadrat impedansi dan admitansi karakteristik transformator. Bila impedansi beban berupa kapasitor, maka akan diubah menjadi induktor dan sebaliknya.

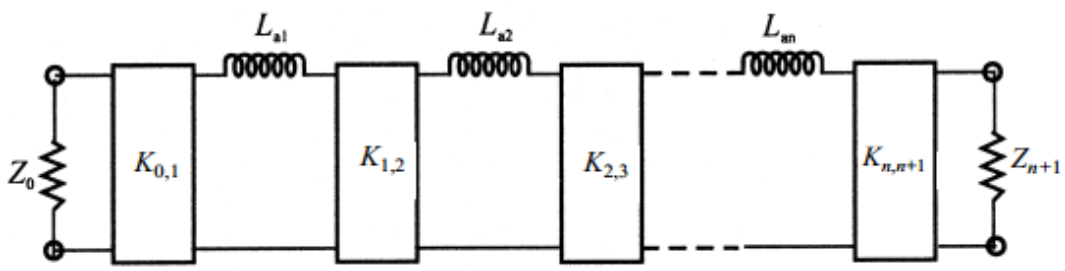

(a)

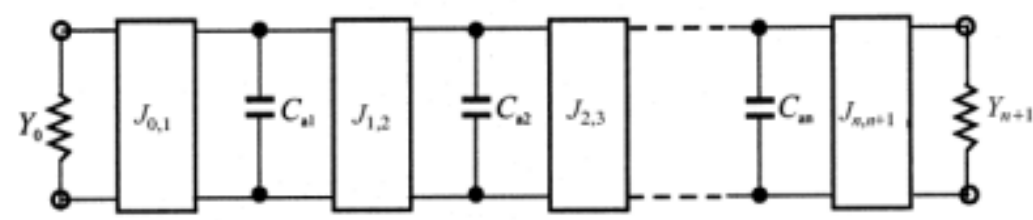

(b)

Gambar 2. Lowpass Filter Prototype dengan Inverter. (a) Rangkaian induktor seri (b) Rangkaian kapasitor paralel

$$
\frac{J_{j, j+1}}{Y_{0}}=\frac{\pi F B W}{2} \frac{1}{\sqrt{\mathrm{g}_{\mathrm{j}} \mathrm{g}_{\mathrm{j}+1}}} \quad \text { untuk } j=1 \text { to } n-1
$$

dimana :

$\mathrm{g}_{0}, \mathrm{~g}_{1} \ldots \mathrm{g}_{\mathrm{n}} \quad$ : elemen lowpass prototype dengan normalisasi cut-off $\Omega_{\mathrm{c}}=1$

$J_{j j+1} \quad$ : admintansi karakteristik dari J-Inverter

Y $\quad$ : admitansi karakteristik dari saluran terminasi

Dan untuk merealisasikan J-Inverter diatas terdapat impedansi karakteristik mode genap dan mode ganjil, dengan persamaan sebagai berikut:

$$
\begin{array}{ll}
\left(Z_{0 e}\right)_{j, j+1}=\frac{1}{Y_{0}}\left[1+\frac{J_{j, j+1}}{Y_{0}}+\left(\frac{J_{j, j+1}}{Y_{0}}\right)^{2}\right] & j=0 \text { to } n \\
\left(Z_{0 o}\right)_{j, j+1}=\frac{1}{Y_{0}}\left[1-\frac{J_{j, j+1}}{Y_{0}}+\left(\frac{J_{j, j+1}}{Y_{0}}\right)^{2}\right] & j=0 \text { to } n
\end{array}
$$

\section{Saluran Transmisi Mikrostrip (Pozar, 1998)}

Mikrostrip merupakan media transmisi yang digunakan di dalam rangkaian microwave. Mikrostrip terdiri dari saluran strip (konduktor) dan sebuah konduktor ground plane yang dipisahkan oleh medium dielektrik dengan konstanta dielektrik $\left(\varepsilon_{\mathrm{r}}\right)$. Sebagian medan elektromagnetik yang berada di udara $\left(\varepsilon_{\mathrm{r}}=1\right)$, akan meradiasi rangkaian apabila tidak ada shielding diatas medium dielektrik. Jadi, saluran mikrostrip merupakan sebuah saluran dengan dielektrik homogen yang lebih besar dari satu, tapi lebih kecil dari konstanta dielektrik bahan $\left(\varepsilon_{\mathrm{r}}\right)$. Konstanta dielektrik ini disebut konstanta dielektrik efektif $\left(\varepsilon_{\text {rff }}\right)$. Ini merupakan saluran transmis sederhana dengan kecepatan fase $\left(v_{p}=c\right)$ dan konstanta propagasi $\left(\beta=\mathrm{k}_{0}\right)$. 


$$
\begin{aligned}
& v_{p}=\frac{c}{\sqrt{\epsilon_{e}}} \\
& \beta=k_{o} \sqrt{\epsilon_{e}}
\end{aligned}
$$

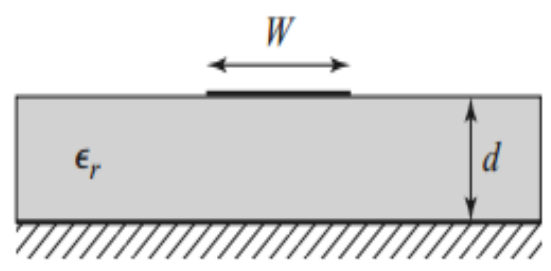

Gambar 3. Saluran Mikrostrip

Hubungan antara konstanta dielektrik efektik $\left(\epsilon_{e}\right)$, impedansi karakteristik $\left(Z_{0}\right)$ dengan $(W / h)$ dapat diperoleh dari konstanta dielektrik efektif dengan persamaan:

$$
\epsilon_{e}=\frac{\varepsilon_{r}+1}{2}+\frac{\varepsilon_{r}-1}{2} \frac{1}{\sqrt{1+12 d / W}}
$$

Dengan nilai dimensi W/d yang diketahui, kita dapat menghitung impedansi karakteristik dengan persamaan berikut:

$$
Z_{0}=\left\{\begin{array}{cc}
\frac{60}{\sqrt{\epsilon_{e}} \ln \left(\frac{8 d}{W}+\frac{W}{4 d}\right)} & \mathrm{W} / \mathrm{d} \leq 1 \\
\frac{120 \pi}{\sqrt{\epsilon_{e}}\left[\frac{W}{d}+1.393+0.667 \ln \left(\frac{W}{d}+1.444\right)\right]} & \mathrm{W} / \mathrm{d} \geq 1
\end{array}\right.
$$

Dan untuk nilai $Z_{0}$ dan $\epsilon_{e}$ yang sudah diketahui, rasio $\mathrm{W} / \mathrm{d}$ dapat dicari menggunakan persamaan berikut:

$$
\frac{W}{d}=\left\{\begin{array}{cc}
\frac{8 e^{A}}{e^{2 A}-2} & \mathrm{~W} / \mathrm{d}<2 \\
\frac{2}{\pi}\left[B-1-\ln (2 B-1)\left\{\ln (B-1)+0.39-\frac{0.61}{\epsilon_{r}}\right\}\right] & \mathrm{W} / \mathrm{d}>2
\end{array}\right.
$$

dengan:

$$
\begin{aligned}
& A=\frac{Z_{0}}{60} \sqrt{\frac{\varepsilon_{r}+1}{2}}+\frac{\varepsilon_{r}-1}{2}\left(0.23+\frac{0.11}{\epsilon_{r}}\right) \\
& B=\frac{377 \pi}{2 Z_{0} \sqrt{\epsilon_{e}}}
\end{aligned}
$$

Sementara itu untuk mengetahui nilai panjang saluran mikrostrip $(\mathrm{L})$ apabila telah diketahui nilai $\mathrm{W} / \mathrm{d}$, maka panjang mikrostrip dapat diitung menggunakan persamaan:

$$
L=\frac{\left(\frac{\pi}{180^{0}}\right)}{\sqrt{\epsilon_{e} k_{o}}}
$$


dengan :

$$
k_{o}=\frac{2 \pi f}{c}
$$

\section{Hairpin-Line (Lancaster, 2001)}

Hairpin-line bandpass filters adalah filter yang mempunyai struktur tersusun rapi. Filter tersebut mempunyai konsep yang didapat dengan lipatan resonator dari paralle/-coupled, half-wavelength resonator filters, dan mempunyai bentuk " $U$ ".
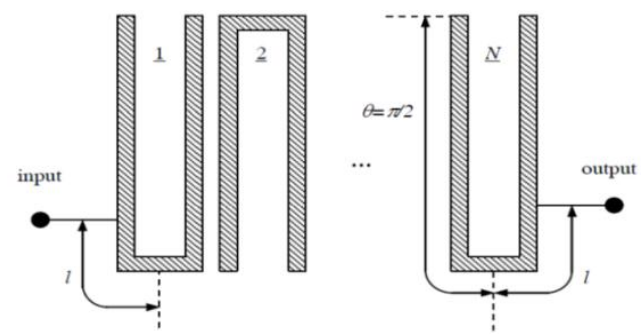

\section{Gambar 4. Konfigurasi Hairpin-Line Band Pass Filters}

Saluran dilipat berbentuk " $U$ " dan disusun dalam model sehingga seluruh filter dapat lebih ringkas. Untuk mendisain filter Hairpin dapat dengan teknik kopling dimana koefisien kopling dapat ditentukan oleh persamaan:

$$
M_{i, i+1}=\frac{F B W}{\sqrt{\mathrm{g}_{\mathrm{i}} \mathrm{g}_{\mathrm{i}+1}}} \quad \text { for } i=1 \text { to } n-1
$$

dimana: FBW = fractional bandwidth

$\mathrm{g}_{\mathrm{n}}=$ parameter lowpass chebyshev

Kemudian dari nilai koefisien kopling digunakan untuk menentukan jarak antar resonator (s) dari koling resonator. Hubungan koefisien kopling dengan $s$ dapat dilihat pada gambar di bawah ini.

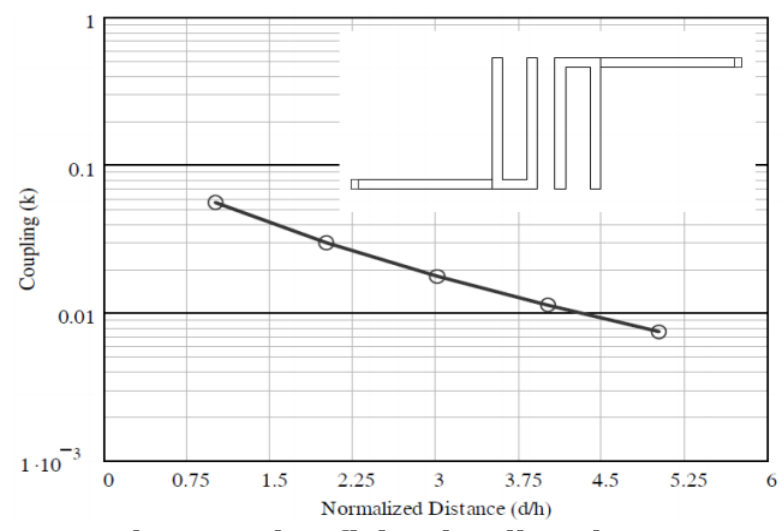

Gambar 5. Hubungan koefisien kopling dengan separation

Faktor kualitas eksternal resonator pada input $\mathrm{Q}_{\mathrm{e} 1}$ dan pada output $\mathrm{Q}_{\mathrm{en}}$ diberikan oleh persamaan di bawah ini:

$$
Q_{e n}=\frac{g_{n} g_{n+1}}{F B W}
$$


Pada filter Hairpin terdapat saluran terkopel dan tidak terkopel. Untuk menentukan saluran yang terkopel terpengaruh dari impedansi mode genap dan mode ganjil, yang diberikan oleh persamaan berikut:

$$
l_{j}=\frac{\lambda_{\mathrm{g}}}{4\left(\sqrt{\left(\epsilon_{r e}^{e}\right)_{j} x\left(\epsilon_{r e}^{o}\right)_{j}}\right)^{1 / 2}}
$$

Sedangkan untuk saluran tidak terkopel atau sering disebut dengan slide factor, panjang slide factor yang berlebih akan mengakibatkan redaman filter menjadi bertambah, namun jika terlalu pendek akan mengakibatkan adanya self-coupling yaitu kopling diantara saluran yang sama. Untuk panjang slide factor pada umumnya 1 sampai 3 kali lebar resonator atau 2-2.5 kali dari jarak antar resonator itu sendiri. Persamaan untuk mencari panjang slide factor dapat dilihat pada persamaan berikut:

$$
b=\frac{\lambda_{\mathrm{g}}}{4}-\left(\theta_{c}+W\right)
$$

dengan: $\theta_{c}=$ electrical length $=90^{\circ}$

Untuk menentukan posisi tapping $(t)$ dengan menggunakan persamaan berikut:

$$
t=\frac{2 L}{\pi} \sin ^{-1}\left(\sqrt{\frac{2}{\pi} \frac{Z_{0} / Z_{r}}{Q_{e}}}\right)
$$

dengan : $\mathrm{L} \quad=$ panjang resonator $\lambda / 4$

$Z_{0} \quad=$ impedansi terminasi

$\mathrm{Z}_{\mathrm{r}} \quad$ = impedansi karakteristik saluran

\section{MODEL SISTEM}

\subsection{Spesifikasi Alat}

Perancangan dimulai dengan menentukan spesifikasi bandpass filter kemudian data spesifikasi dihitung menggunakan persamaan sesuai dengan teori, dari perhitungan didapatkan hasil perancangan. Setelah itu tahap selanjutnya adalah simulasi menggunakan software CST Microwave Studio Suite untuk mengevaluasi dari hasil perancangan. Jika dari hasil simulasi belum didapatkan hasil yang sesuai dengan spesifikasi maka dilakukan tunning atau optimasi sampai didapatkan hasil yang diharapkan. Spesifikasi alat yang akan dirancang harus sesuai dengan penerapan fungsi filter tersebut. Adapun spesifikasi bandpass filter yang dirancang sesuai dengan Synthetic Aperture Radar (SAR) pada penelitian ini adalah sebagai berikut (J. T. Sri Sumantyo, 2009).
1. Frekuensi
: $1.265-1.275 \mathrm{MHz}$
2. Bandwidth
: $10 \mathrm{MHz}$
3. Frekuensi tengah
: $1.270 \mathrm{MHz}$
4. Return Loss
$:<-14 \mathrm{~dB}$
5. Respon Frekuensi : Chebyshev dengan ripple $0.1 \mathrm{~dB}$
6. Impedansi output : $50 \Omega$
7. Ketajaman slope : $-120 \mathrm{~dB} /$ decade (-36 dB/oktaf)
8. Tipe Mikrostrip
: Hairpin-Line 
Bahan dielektrik yang digunakan pada perancangan bandpass filter ini adalah epoxy FR4, dengan karakteristik substrat sebagai berikut :

1. Permitivitas dielektrik bahan $\left(\varepsilon_{\mathrm{r}}\right) \quad: 4.4$

2. Tebal dielektrik (d) : $1.6 \mathrm{~mm}$

3. Tebal konduktor $(\mathrm{t}) \quad: 0.035 \mathrm{~mm}$

\subsection{Tahap Perancangan}

Blok Sistem secara umum dari Shyntetic Aperture radar (SAR) terdiri dari bagian antena, blok transmisi yang di dalamnya termasuk bagian sensor, blok digital signal processor dan data recording. Sedangkan filter terdapat pada sisi transmisi baik transmitter ataupun receiver.

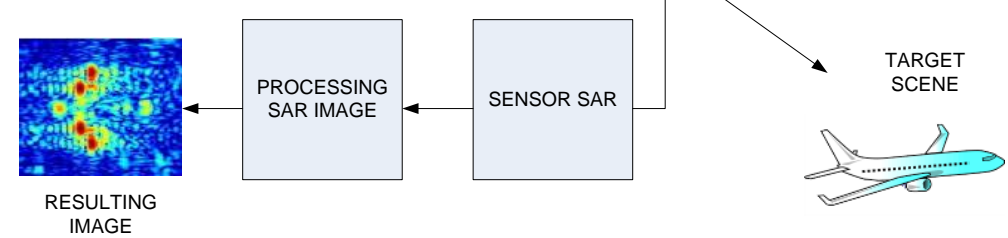

Gambar 6. Synthetic Aperture Radar (SAR)

ANTENA

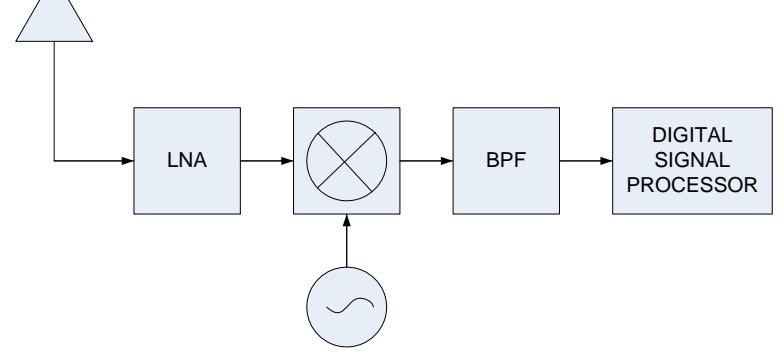

Gambar 7. Blok Transmisi (Penerima) untuk aplikasi Synthetic Aperture Radar (SAR)

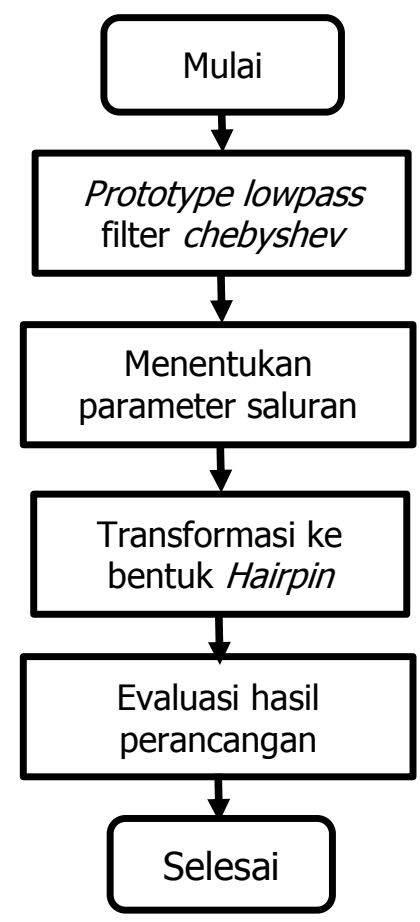

Gambar 8. Diagram Alir Perancangan 
Perancangan BPF pada penelitian ini dilakukan dengan menggunakan teknik kopling. Desain filter dimulai dengan beberapa tahap yaitu menentukan nilai prototype lowpass filter chebyshev, menentukan parameter saluran terkopel, dan transformasi ke bentuk Hairpin. Alur perancangan filter diperlihatkan pada gambar 8 .

\subsubsection{Prototype Lowpass Filter Chebyshev}

Tahapan ini untuk menentukan nilai fractional bandwidth (FBW) dan jumlah elemen filter (orde) minimal fo $=1.27 \mathrm{GHz}$. Didapatkan Fractional Bandwidth (FBW) :

$$
\begin{aligned}
& F B W=\frac{B W}{f o}=\frac{10 \times 10^{6}}{1.27 \times 10^{9}}=0.0079 \\
& \left|\frac{\omega}{\omega_{c}}\right|=\frac{2}{F B W} \times\left(\frac{\omega-\omega_{0}}{\omega_{0}}\right)=\frac{2}{0.0079} \times\left(\frac{1.27-1.255}{1.255}\right)=3.0339 \\
& \Omega=\Omega_{S} \\
& n \geq \frac{\cosh ^{-1} \sqrt{\frac{10^{0.1 L_{A r}-1}}{10^{0.1} L_{A s-1}}} \geq \frac{\cosh ^{-1} \sqrt{\frac{10^{0.1 \times 70}-1}{10^{0.1 \times 0.1}-1}}}{\cosh ^{-1} \Omega_{S}} \geq 5.9911 \approx 6}{\cosh ^{-1} 3.0339}=6
\end{aligned}
$$

Dari perhitungan diatas didapatkan jumlah elemen filter dengan frekuensi stopband 1.255 $\mathrm{GHz}$ dengan redaman minimum $>70 \mathrm{~dB}$ adalah orde $6(\mathrm{n}=6)$.

Tabel 1. Nilai prototype lowpass chebyshev orde 6 dengan ripple $0.1 \mathrm{~dB}$ (Chris Bowick, 1997)

\begin{tabular}{|c|c|c|c|c|c|c|c|}
\hline $\mathbf{n}$ & $\mathbf{g}_{\mathbf{1}}$ & $\mathbf{g}_{\mathbf{2}}$ & $\mathbf{g}_{\mathbf{3}}$ & $\mathbf{\mathbf { g } _ { 4 }}$ & $\mathbf{\mathbf { g } _ { 5 }}$ & $\mathbf{\mathbf { g } _ { \mathbf { 6 } }}$ & $\mathbf{g} \mathbf{7}$ \\
\hline 6 & 1.1681 & 1.4039 & 2.0562 & 1.5170 & 1.9029 & 0.8618 & 1.3554 \\
\hline
\end{tabular}

\subsubsection{Menetukan Parameter Saluran Terkopel (Lancaster, 2001)}

Tabel 2. Nilai J-Inverter

\begin{tabular}{|c|c|}
\hline Kode J-Inverter & Nilai J-Inverter \\
\hline J_01 & 0.1029 \\
\hline J_45 & 0.0073 \\
\hline J_12 & 0.0097 \\
\hline J_56 & 0.0097 \\
\hline J_23 & 0.0073 \\
\hline J_67 & 0.1029 \\
\hline J_34 & 0.0070 \\
\hline
\end{tabular}

Setelah mendapatkan nilai elemen untuk prototype lowpass filter, tahap selanjutnya adalah menentukan nilai J-Inverter untuk mengkonversi menjadi elemen mikrostrip. Kemudian untuk perhitungannya dapat menggunakan persamaan (6). Hasil perhitungan nilai J-Inverter diperlihatkan pada tabel 2. 


\subsubsection{Impedansi Karakterikstik ( $\left.Z_{0}\right)$}

Nilai impedansi karakteristik mode genap dan mode ganjil pada setiap resonator dengan menggunakan persamaan (2.4a).

Tabel 3. Nilai impedansi karakteristik mode genap dan mode ganjil pada setiap resonator

\begin{tabular}{|c|c|}
\hline Mode Genap $(\boldsymbol{\Omega})$ & Mode Ganjil $(\boldsymbol{\Omega})$ \\
\hline$\left(\mathrm{Z}_{0 \mathrm{e}}\right)_{01}=55.6729$ & $\left(\mathrm{Z}_{0 \mathrm{o}}\right)_{01}=45.3854$ \\
\hline$\left(\mathrm{Z}_{0 \mathrm{e}}\right)_{12}=50.4873$ & $\left(\mathrm{Z}_{00}\right)_{12}=49.5220$ \\
\hline$\left(\mathrm{Z}_{0 \mathrm{e}}\right)_{23}=50.3664$ & $\left(\mathrm{Z}_{00}\right)_{23}=49.6388$ \\
\hline$\left(\mathrm{Z}_{0 \mathrm{e}}\right)_{34}=50.3524$ & $\left(\mathrm{Z}_{00}\right)_{34}=49.6525$ \\
\hline$\left(\mathrm{Z}_{0 \mathrm{e}}\right)_{45}=50.3664$ & $\left(\mathrm{Z}_{00}\right)_{45}=49.6388$ \\
\hline$\left(\mathrm{Z}_{0 \mathrm{e}}\right)_{56}=50.4873$ & $\left(\mathrm{Z}_{00}\right)_{56}=49.5220$ \\
\hline$\left(\mathrm{Z}_{0 \mathrm{e}}\right)_{67}=55.6729$ & $\left(\mathrm{Z}_{00}\right)_{67}=45.3854$ \\
\hline
\end{tabular}

\subsubsection{Dimensi Resonator Mikrostrip (Pozar, 1998)}

Setelah mendapatkan nilai elemen-elemen mikrostrip dan impedansi karakteristik tiap resonator, selanjutnya dengan menggunakan persamaan (7) dan (8) nilai konstanta dielektrik efektif $\left(\epsilon_{e}\right)$ dan impedansi karakteristik saluran $\left(Z_{r}\right)$ dapat dihitung sebagai berikut $(\varepsilon \mathrm{r}=4.3 ; \mathrm{w}=2 \mathrm{~mm} ; \mathrm{d}=1.6 \mathrm{~mm})$ :

$$
\begin{gathered}
\epsilon_{e}=\frac{4.3+1}{2}+\frac{4.3-1}{2}\left(1+\frac{12 \times 1.6}{2}\right)^{-0.5}=3.0914 \\
Z_{r}=\frac{120 \pi}{\sqrt{3.1567}\left[\frac{2}{1.6}+1.393+0.677 \operatorname{Ln}\left(\frac{2}{1.6}+1.444\right)\right]}=67.3653 \Omega \\
A=\frac{50}{60} \sqrt{\frac{4.3+1}{2}+\frac{4.3-1}{4.3+1}\left(0.23+\frac{0.11}{4.3}\right)=1.5157} \\
\frac{W}{d}=\frac{8 e^{1.5157}}{e^{2(1.5157)}-2}=1.5014 \\
W_{c}=1.9449 \times 1.6=3.1666 \mathrm{~mm}
\end{gathered}
$$

Nilai $W_{c}$ merupakan lebar dari saluran coupled input dan output yaitu $3.1666 \mathrm{~mm}$. Panjang saluran transmisi (transmission line) didapat dari :

$$
\begin{gathered}
\epsilon_{e}=\frac{4.3+1}{2}+\frac{4.3-1}{2}\left(1+\frac{12 \times 1.6}{3.1118}\right)^{-0.5}=3.2662 \\
k_{o}=\frac{2 \pi 1.27 \times 10^{9}}{3 \times 10^{8}}=26.5853 \mathrm{~m}^{-1}
\end{gathered}
$$

Panjang resonator transmission line dapat ditentukan berdasarkan persamaan diatas, sehingga:

$$
L=\frac{\left(\frac{\pi}{180^{0}}\right)}{\sqrt{3.2662 \times 26.5853 m^{-1}}} \times 3.1666=1.1238 \mathrm{~mm}
$$




$$
\begin{gathered}
\text { Koefisien Kopling } \\
M_{0,1}=\frac{0.0079}{\sqrt{1 \times 1.1681}}=0.0073
\end{gathered}
$$

Faktor Kualitas

$$
Q_{0,1}=\frac{1 \times 1.1681}{0.0079}=148.3487
$$

Tabel 4. Nilai Koefisien Kopling dan Faktor Kualitas

\begin{tabular}{|c|c|}
\hline Koefisien Kopling & Faktor Kualitas \\
\hline$M_{0,1}=0.0073$ & $\mathrm{Q}_{0,1}=148.3487$ \\
\hline$M_{1,2}=0.0061$ & $\mathrm{Q}_{1,2}=208.2667$ \\
\hline$M_{2,3}=0.0046$ & $\mathrm{Q}_{2,3}=366.6108$ \\
\hline$M_{3,4}=0.0045$ & $\mathrm{Q}_{3,4}=396.1454$ \\
\hline$M_{4,5}=0.0046$ & $\mathrm{Q}_{4,5}=366.6108$ \\
\hline$M_{5,6}=0.0061$ & $\mathrm{Q}_{5,6}=208.2667$ \\
\hline$M_{6,7}=0.0073$ & $\mathrm{Q}_{6,7}=148.3487$ \\
\hline
\end{tabular}

Tabel 5. Nilai Resonator

\begin{tabular}{|c|c|}
\hline Resonator & $\begin{array}{c}\text { Jarak Resonator } \\
(\mathbf{m m})\end{array}$ \\
\hline$s_{01}$ & 0.1500 \\
\hline$s_{12}$ & 0.8000 \\
\hline$s_{23}$ & 2.0000 \\
\hline$s_{34}$ & 3.0000 \\
\hline$s_{45}$ & 2.0000 \\
\hline$s_{56}$ & 0.8000 \\
\hline$s_{67}$ & 0.1500 \\
\hline
\end{tabular}

\subsubsection{Panjang saluran tiap resonator}

Untuk menentukan panjang gelombang terbimbing $\left(\lambda_{g}\right)$ setiap resonator terlebih dahulu mencari nilai konstanta dielektrik mode genap dan mode ganjil pada masing-masing resonator.

Tabel 6. Konstanta Dielektrik Efektif tiap Resonator

\begin{tabular}{|c|c|c|c|}
\hline Resonator & $\boldsymbol{\epsilon}_{\boldsymbol{e}}$ & $\boldsymbol{\epsilon}_{\boldsymbol{r} \boldsymbol{e}}^{\boldsymbol{e}}$ & $\boldsymbol{\epsilon}_{\boldsymbol{r} \boldsymbol{e}}^{\boldsymbol{o}}$ \\
\hline 01 & 3.2294 & 3.0941 & 2.7275 \\
\hline 12 & 3.3122 & 3.1421 & 2.7407 \\
\hline 23 & 3.3936 & 3.1925 & 2.7572 \\
\hline 34 & 3.5285 & 3.2802 & 2.7952 \\
\hline 45 & 3.4241 & 3.2120 & 2.7644 \\
\hline 56 & 3.5039 & 3.2640 & 2.7870 \\
\hline 67 & 3.1302 & 3.0402 & 2.7155 \\
\hline
\end{tabular}

Tabel 7. Panjang gelombang terbimbing tiap resonator

\begin{tabular}{|c|c|}
\hline$\left(\boldsymbol{\lambda}_{\mathrm{g}}\right)_{\mathbf{0 1}}$ & $\left(\boldsymbol{\lambda}_{\mathrm{g}} / \mathbf{4}\right)_{\mathbf{0 1}}$ \\
\hline$\left(\lambda_{\mathrm{g}}\right)_{01}=81.3141$ & $\left(\lambda_{\mathrm{g}} / 4\right)_{01}=20.3285$ \\
\hline$\left(\lambda_{\mathrm{g}}\right)_{12}=80.4964$ & $\left(\lambda_{\mathrm{g}} / 4\right)_{12}=20.1241$ \\
\hline$\left(\lambda_{\mathrm{g}}\right)_{23}=79.6195$ & $\left(\lambda_{\mathrm{g}} / 4\right)_{23}=19.9049$ \\
\hline$\left(\lambda_{\mathrm{g}}\right)_{34}=78.0120$ & $\left(\lambda_{\mathrm{g}} / 4\right)_{34}=19.5030$ \\
\hline$\left(\lambda_{\mathrm{g}}\right)_{45}=79.2733$ & $\left(\lambda_{\mathrm{g}} / 4\right)_{45}=19.8183$ \\
\hline$\left(\lambda_{\mathrm{g}}\right)_{56}=78.3203$ & $\left(\lambda_{\mathrm{g}} / 4\right)_{56}=19.5801$ \\
\hline$\left(\lambda_{\mathrm{g}}\right)_{67}=82.2133$ & $\left(\lambda_{\mathrm{g}} / 4\right)_{67}=20.5533$ \\
\hline
\end{tabular}




\subsubsection{Transformasi ke bentuk Hairpin}

\section{Slide factor dan panjang saluran terkopel}

Untuk menentukan panjang slide factor, terlebih dahulu harus menentukan panjang saluran dengan menggunakan persamaan (22). Didapatkan hasil perhitungan sebagai berikut:

$$
l_{01}=\frac{81.3147}{(\sqrt{3.0941 \times 2.7275})^{1 / 2}}=47.7078 \mathrm{~mm}
$$

Dari perhitungan diatas didapatkan nilai panjang saluran terkopel tiap resonator seperti berikut:

Tabel 8. Panjang gelombang terbimbing tiap resonator

\begin{tabular}{|c|c|}
\hline Panjang Saluran terkopel resonator ke- & Panjang Saluran terkopel resonator \\
\hline$l_{01}$ & $47.7078 \mathrm{~mm}$ \\
\hline$l_{12}$ & $46.9901 \mathrm{~mm}$ \\
\hline$l_{23}$ & $46.2243 \mathrm{~mm}$ \\
\hline$l_{34}$ & $44.8315 \mathrm{~mm}$ \\
\hline$l_{45}$ & $45.9232 \mathrm{~mm}$ \\
\hline$l_{56}$ & $45.0975 \mathrm{~mm}$ \\
\hline$l_{67}$ & $48.5014 \mathrm{~mm}$ \\
\hline
\end{tabular}

Setelah panjang saluran terkopel diketahui kita dapat menentukan panjang slide factor dengan persamaan (23). Berikut perhitungan untuk mencari nilai slide factor:

$$
b_{01}=20.3285-\left(90^{0}+2\right)=17.5435 \mathrm{~mm}
$$

Hasil perhitungan dari persamaan diatas, didapatkan panjang slide factor tiap resonator adalah sebagai berikut:

Tabel 9. Nilai Slide Factor tiap resonator

\begin{tabular}{|c|c|}
\hline Slide factor resonator ke- & Slide factor resonator \\
\hline$b_{01}$ & $17.5435 \mathrm{~mm}$ \\
\hline$b_{12}$ & $17.3391 \mathrm{~mm}$ \\
\hline$b_{23}$ & $17.1199 \mathrm{~mm}$ \\
\hline$b_{34}$ & $16.7180 \mathrm{~mm}$ \\
\hline$b_{45}$ & $17.0333 \mathrm{~mm}$ \\
\hline$b_{56}$ & $16.7951 \mathrm{~mm}$ \\
\hline$b_{67}$ & $17.7683 \mathrm{~mm}$ \\
\hline
\end{tabular}

Pada perancangan filter Hairpin ini menggunakan teknik pencatuan Tap-line. Untuk menentukan jarak tapping pada resonator dapat dihitung menggunakan persamaan (24).

Hasil perhitungan tapping adalah sebagai berikut:

$$
\begin{aligned}
t_{\text {input }} & =0.8790 \mathrm{~mm} \\
t_{\text {output }} & =0.8943 \mathrm{~mm}
\end{aligned}
$$


Tabel 10. Parameter-Parameter pada Resonator

\begin{tabular}{|c|c|c|c|c|}
\hline $\begin{array}{c}\text { Resonator } \\
\text { ke- }\end{array}$ & $\begin{array}{c}\text { Lebar } \\
\text { Resonator } \\
\mathbf{( W )}\end{array}$ & $\begin{array}{c}\text { Jarak } \\
\text { Resonator } \\
(\mathbf{s})\end{array}$ & $\begin{array}{c}\text { Panjang } \\
\text { Resonator } \\
\mathbf{( I )}\end{array}$ & $\begin{array}{c}\text { Slide Factor } \\
\text { (b) }\end{array}$ \\
\hline 1 & $2 \mathrm{~mm}$ & $0.1394 \mathrm{~mm}$ & $47.7078 \mathrm{~mm}$ & $17.5435 \mathrm{~mm}$ \\
\hline 2 & $2 \mathrm{~mm}$ & $0.8000 \mathrm{~mm}$ & $46.9901 \mathrm{~mm}$ & $17.3391 \mathrm{~mm}$ \\
\hline 3 & $2 \mathrm{~mm}$ & $2.0000 \mathrm{~mm}$ & $46.2243 \mathrm{~mm}$ & $17.1199 \mathrm{~mm}$ \\
\hline 4 & $2 \mathrm{~mm}$ & $3.0000 \mathrm{~mm}$ & $44.8315 \mathrm{~mm}$ & $16.7180 \mathrm{~mm}$ \\
\hline 5 & $2 \mathrm{~mm}$ & $2.0000 \mathrm{~mm}$ & $45.9232 \mathrm{~mm}$ & $17.0333 \mathrm{~mm}$ \\
\hline 6 & $2 \mathrm{~mm}$ & $0.8000 \mathrm{~mm}$ & $45.0975 \mathrm{~mm}$ & $16.7951 \mathrm{~mm}$ \\
\hline 7 & $2 \mathrm{~mm}$ & $0.1271 \mathrm{~mm}$ & $48.5014 \mathrm{~mm}$ & $17.7683 \mathrm{~mm}$ \\
\hline
\end{tabular}

Dari perancangan hairpin band pass filter diatas didapatkan layout gambar rangkaian sebagai berikut:

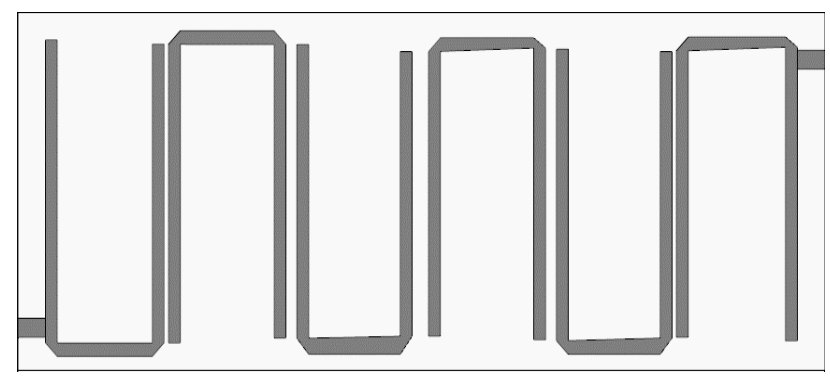

Gambar 9. Layout Hairpin Band Pass Filter

\subsection{Tahap Simulasi}

Sebelum ke tahap pabrikasi, langkah selanjutnya yang dilakukan adalah melakukan simulasi menggunakan bantuan simulator. Pada tahap simulasi ini menggunakan simulator CST Studio Suite. Untuk langkah-langkah simulasi bisa dilihat pada bagian lampiran. Gambar di bawah ini menunjukkan respon frekuensi dari hasil simulasi.

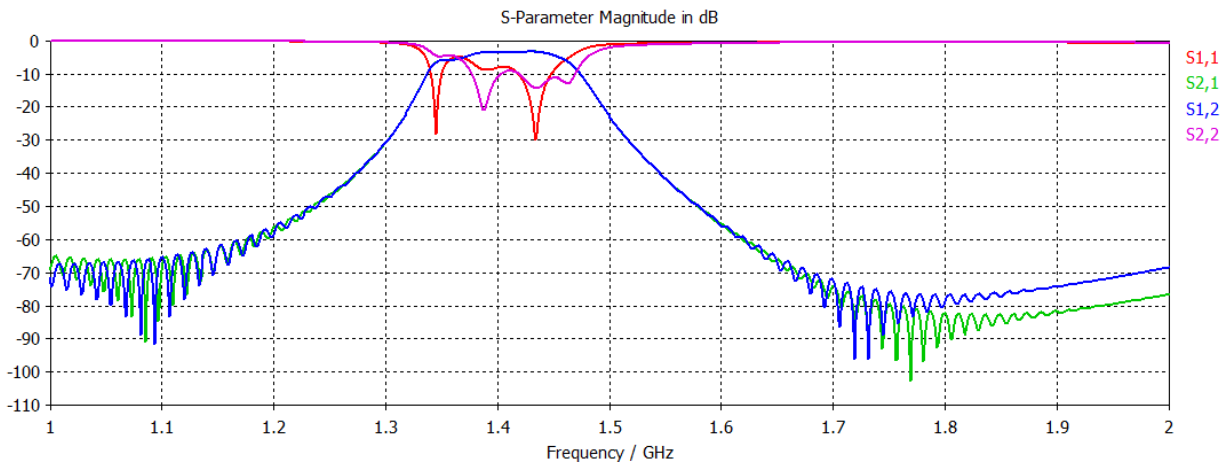

Gambar 10. Respon Frekuensi Hasil simulasi

Dari gambar 10 diatas dapat dilihat bahwa respon frekuensi berada pada rentang $1.34 \mathrm{GHz}-$ $1.46 \mathrm{GHz}$, sehingga perlu dilakukan tunning atau optimasi agar didapatkan respon frekuensi yang diharapkan yaitu pada rentang $1.265 \mathrm{GHz}-1.275 \mathrm{GHz}$. 


\subsection{Tahap Optimasi}

Karena pada hasil perhitungan dengan hasil simulasi akan ada perbedaan maka dilakukan optimasi yang menghasilkan ukuran layout yang berbeda dengan hasil perhitungan. Layout PCB yang sudah dioptimasi sebagai berikut:

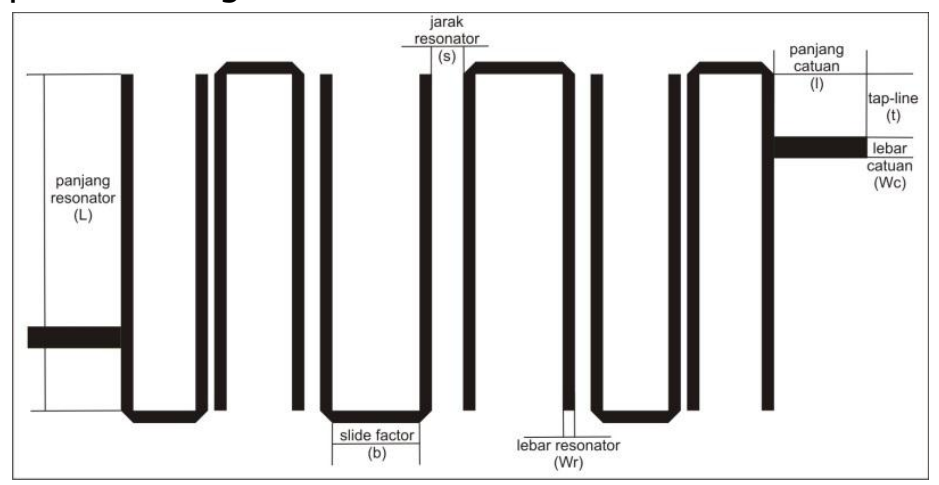

Gambar 11. Layout Hairpin Band Pass filter Setelah Optimasi

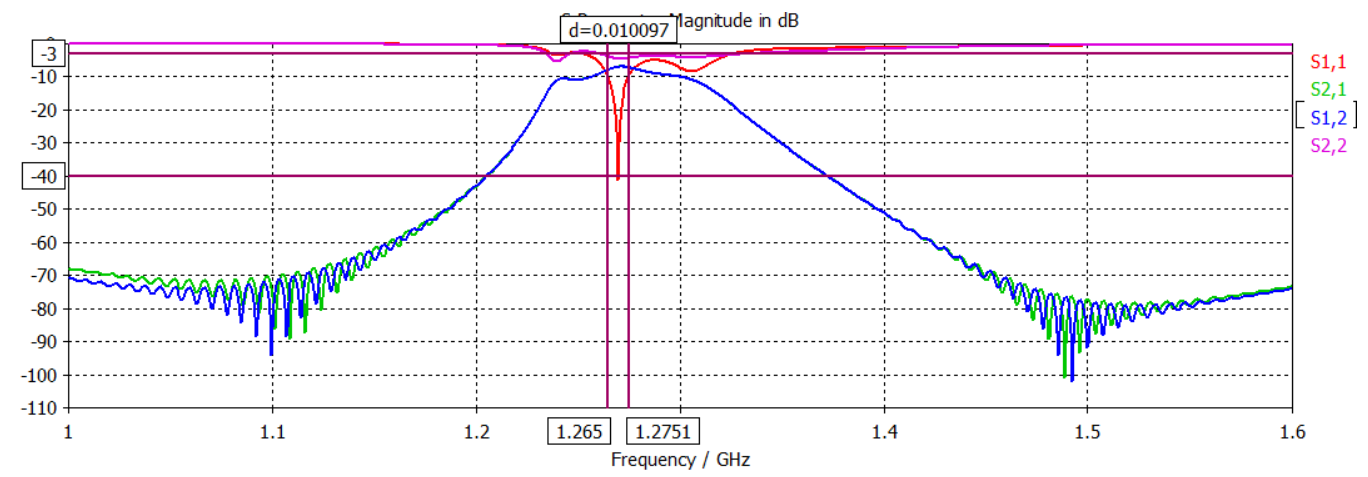

Gambar 12. Hasil Optimasi menggunakan CST Suite Studio

Nilai parameter-parameter resonator Hairpin menjadi berubah setelah melakukan optimasi, berikut adalah nilai parameter-parameternya:

Tabel 11. Parameter-parameter pada resonator Hairpin setelah optimasi

\begin{tabular}{|c|c|c|c|c|}
\hline $\begin{array}{c}\text { Resonator } \\
\text { ke- }\end{array}$ & $\begin{array}{c}\text { Lebar } \\
\text { Resonator }(\mathbf{W})\end{array}$ & $\begin{array}{c}\text { Jarak Resonator } \\
(\mathbf{s})\end{array}$ & $\begin{array}{c}\text { Panjang } \\
\text { Resonator (I) }\end{array}$ & $\begin{array}{c}\text { Slide } \\
\text { Factor (b) }\end{array}$ \\
\hline 1 & $2 \mathrm{~mm}$ & $0.1394 \mathrm{~mm}$ & $54 \mathrm{~mm}$ & $5 \mathrm{~mm}$ \\
\hline 2 & $2 \mathrm{~mm}$ & $1 \mathrm{~mm}$ & $54 \mathrm{~mm}$ & $5 \mathrm{~mm}$ \\
\hline 3 & $2 \mathrm{~mm}$ & $2.5 \mathrm{~mm}$ & $54 \mathrm{~mm}$ & $5.5 \mathrm{~mm}$ \\
\hline 4 & $2 \mathrm{~mm}$ & $5 \mathrm{~mm}$ & $54 \mathrm{~mm}$ & $8.5 \mathrm{~mm}$ \\
\hline 5 & $2 \mathrm{~mm}$ & $2.5 \mathrm{~mm}$ & $54 \mathrm{~mm}$ & $5.5 \mathrm{~mm}$ \\
\hline 6 & $2 \mathrm{~mm}$ & $1 \mathrm{~mm}$ & $54 \mathrm{~mm}$ & $5 \mathrm{~mm}$ \\
\hline 7 & $2 \mathrm{~mm}$ & $0.1271 \mathrm{~mm}$ & $54 \mathrm{~mm}$ & $5 \mathrm{~mm}$ \\
\hline
\end{tabular}

\section{HASIL PENGUKURAN DAN ANALISIS}

\subsection{Hasil Pengukuran}

\subsubsection{Hasil Pengukuran Return Loss}

Pengukuran Return Loss (S11) menunjukkan karakteristik sinyal yang dipantulkan kembali ke sumber. Semakin kecil nilai Return Loss maka semakin kecil pula daya yang dikembalikan menuju sumber, sehingga daya bisa tersalurkan secara maksimal atau terjadi transfer daya maksimum. Hasil pengukuran dapat dilihat pada Gambar 13. Pada Gambar 13 marker 1 
berada di frekuensi $1252 \mathrm{MHz}$ dengan nilai Return Loss sebesar $-6.671 \mathrm{~dB}$, marker 2 berada di frekuensi $1270 \mathrm{MHz}$ dengan nilai Return Loss sebesar - $9.337 \mathrm{~dB}$, dan marker 3 berada frekuensi $1290 \mathrm{MHz}$ dengan nilai Return Loss s $-6.640 \mathrm{~dB}$. Marker 1 dan marker 3 menunjukkan nilai Return Loss untuk nilai bandwidth pada daerah passband dan marker 2 menunjukkan nilai Return Loss untuk frekuensi tengahnya.

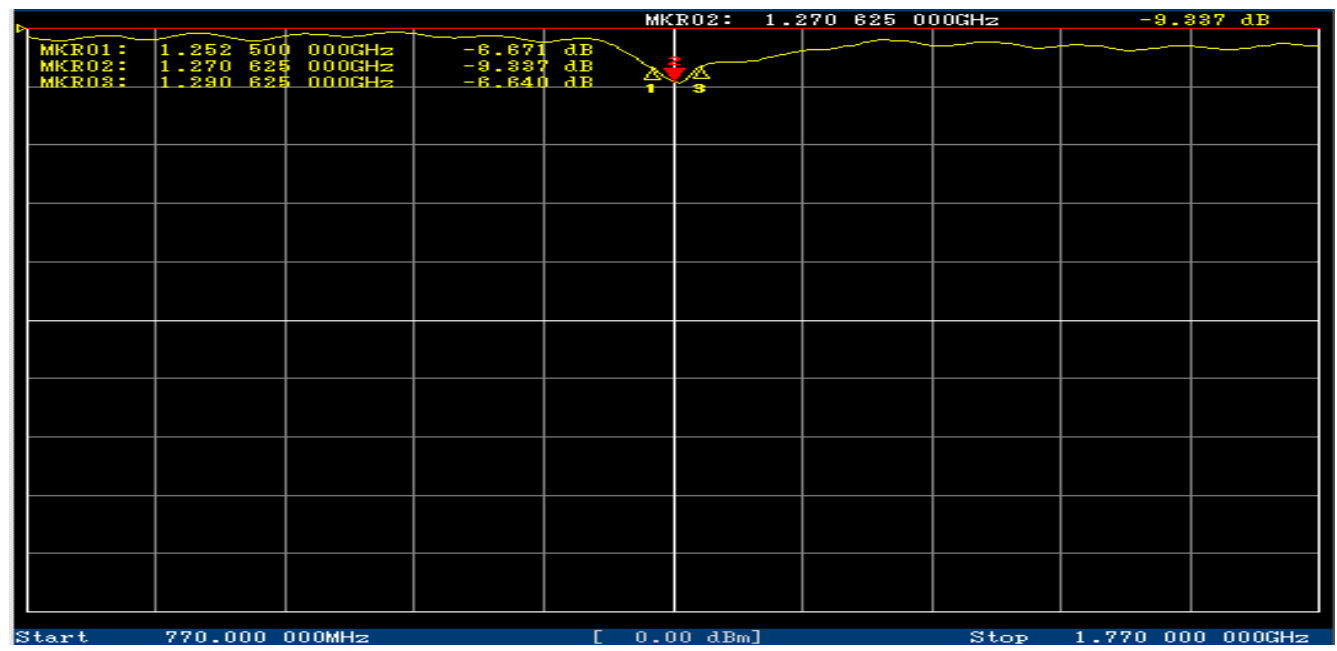

Gambar 13. Hasil Pengukuran Return Loss

\subsubsection{Hasil Pengukuran Insertion Loss}

Insertion Loss menunjukkan karakteristik sinyal yang ditransmisikan dari port input ke port output. Insertion Loss ini disebut juga dengan Scattering Coefficient (S21). Idealnya nilai Insertion Loss adalah $0 \mathrm{~dB}$, namun karena banyak terdapat rugi-rugi dalam filter maka nilai tersebut sulit untuk dicapai. Kemudian untuk hasil pengukuran Insertion Loss dapat dilihat pada Gambar 14.

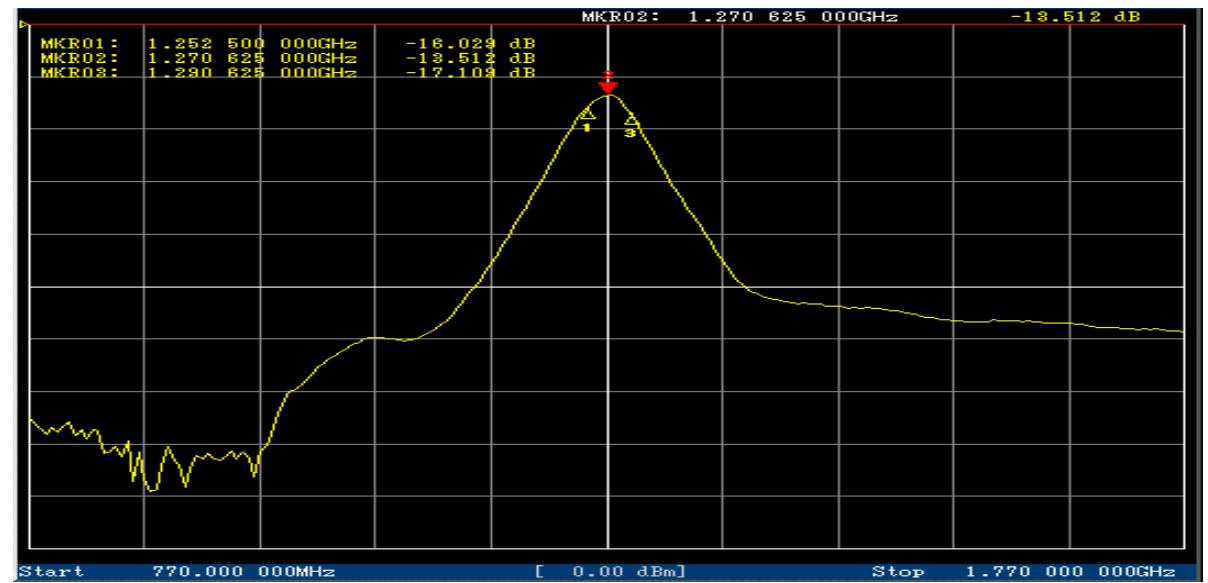

Gambar 14. Hasil Pengukuran Insertion Loss

Pada hasil pengukuran dapat dilihat bahwa nilai Insertion Loss pada marker 2 atau ketika pada frekuensi tengah $1270 \mathrm{MHz}$ adalah $-13.512 \mathrm{~dB}$, artinya saat frekuensi $1270 \mathrm{MHz}$ daya pancar yang keluar dari filter adalah sebesar 1/20 kali dari daya yang masuk ke filter. Sedangkan pada marker 1 dengan frekuensi $1252 \mathrm{MHz}$ nilai Insertion Loss nya adalah $18.022 \mathrm{~dB}$ dan pada marker 3 dengan frekuensi $1290 \mathrm{MHz}$ nilai Insertion Loss nya adalah $17.103 \mathrm{~dB}$. 


\subsubsection{Hasil Pengukuran Respon Fasa}

Respon fasa menunjukkan tingkat linieritas filter yang akan memperngaruhi besar kecilnya delay pada sistem. Berdasarkan hasil pengukuran, tingkat ke linieritas filter dapat dilihat pada gambar berikut ini.

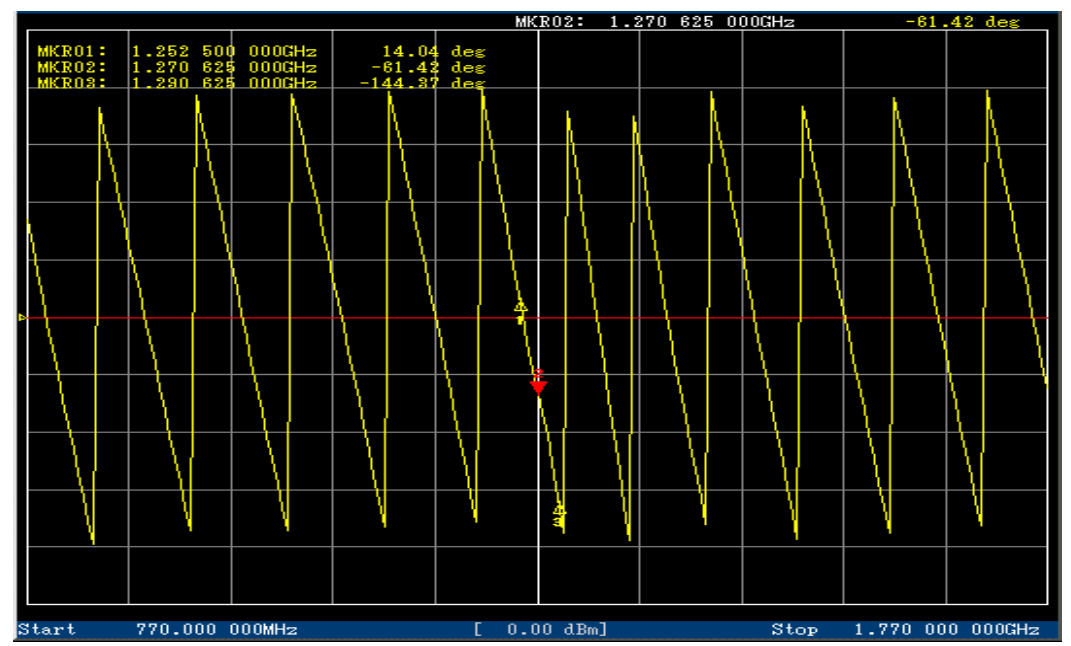

Gambar 15. Hasil Pengukuran Respon Fasa

Pada hasil pengukuran fasa di atas didapatkan hasil pada marker 1 dengan frekuensi 1252 $\mathrm{MHz}$ didapatkan nilai $14.14^{\circ}$, kemudian pada marker 2 dengan frekuensi $1270 \mathrm{MHz}$ didapatkan nilai $-61.43^{\circ}$, dan pada marker 3 dengan frekuensi $1290 \mathrm{MHz}$ didapatkan nilai fasa $-144.87^{\circ}$.

\subsection{Analisis Hasil Pengukuran}

\subsubsection{Analisis Hasil Pengukuran Return Loss}

Berdasarkan hasil pengukuran Return LosS, nilai VSWR pada filter Hairpin dengan frekuensi $1270 \mathrm{MHz}$ adalah 2.044 atau dengan kata lain lebih besar dibandingkan dengan VSWR ideal Persamaan untuk menghitung nilai VSWR dapat dilihat pada persamaan (26) dan (27).

$$
\begin{aligned}
& R L=-20 \log |\Gamma| \\
& V S W R=\frac{1+|\Gamma|}{1-|\Gamma|}
\end{aligned}
$$

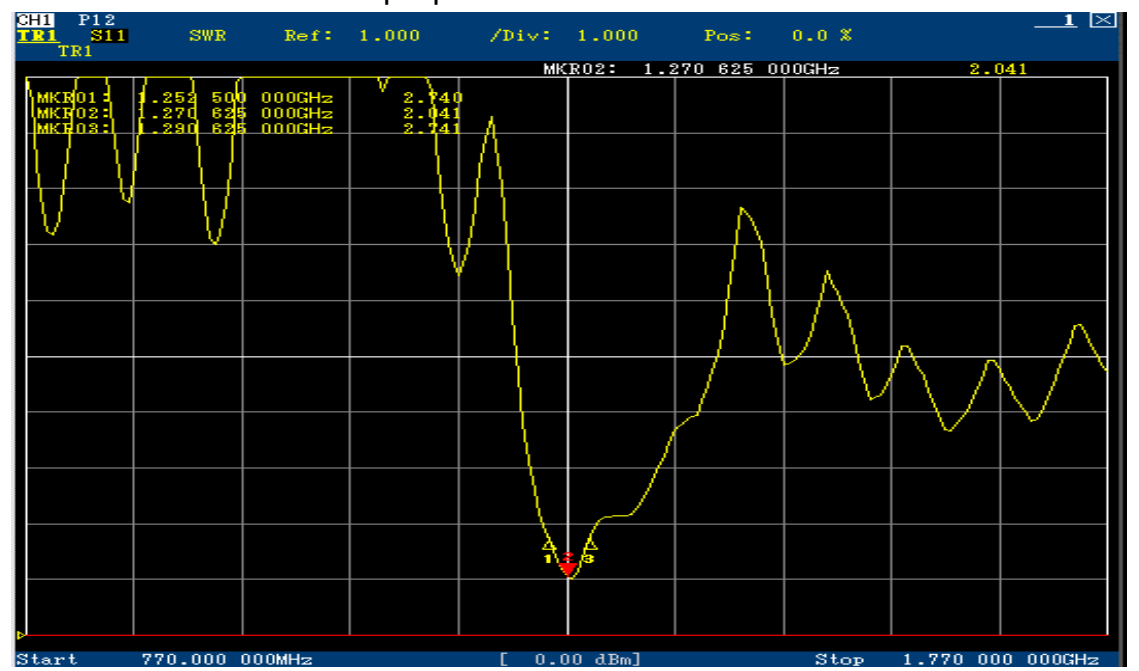

Gambar 16. Hasil Pengukuran VSWR 
VSWR menunjukkan tingkat kesesuaian impedansi (matching impedance) antara saluran filter dengan saluran sumber. Semakin besar nilai VSWR, maka kualitas filter akan semakin jelek karena banyak daya yang dipantulkan kembali menuju sumber.

VSWR ideal mempunyai nilai 1 , namun sangat sulit untuk mendapatkan nilai VSWR $=1$ dalam realisasinya karena terdapat banyak faktor-faktor yang dapat mengakibatkan ketidaksesuaian impedansi antara saluran filter dengan sumber. Beberapa faktornya antara lain:

1. Impedansi Tap-Line tidak tepat $50 \Omega$ dan tidak match dengan impedansi konektor yang digunakan.

2. Proses penyolderan konektor ke saluran akan berpengaruh terhadap nilai impedansi pada Tap-Line.

Dari hasil pengukuran filter menunjukkan banyak daya yang dipantulkan kembali ke sumber, sehingga dalam penerapan filter Hairpin dalam Synthetic Aperture Radar akan mengakibatkan kerugian karena akan banyak daya yang ke sumber.

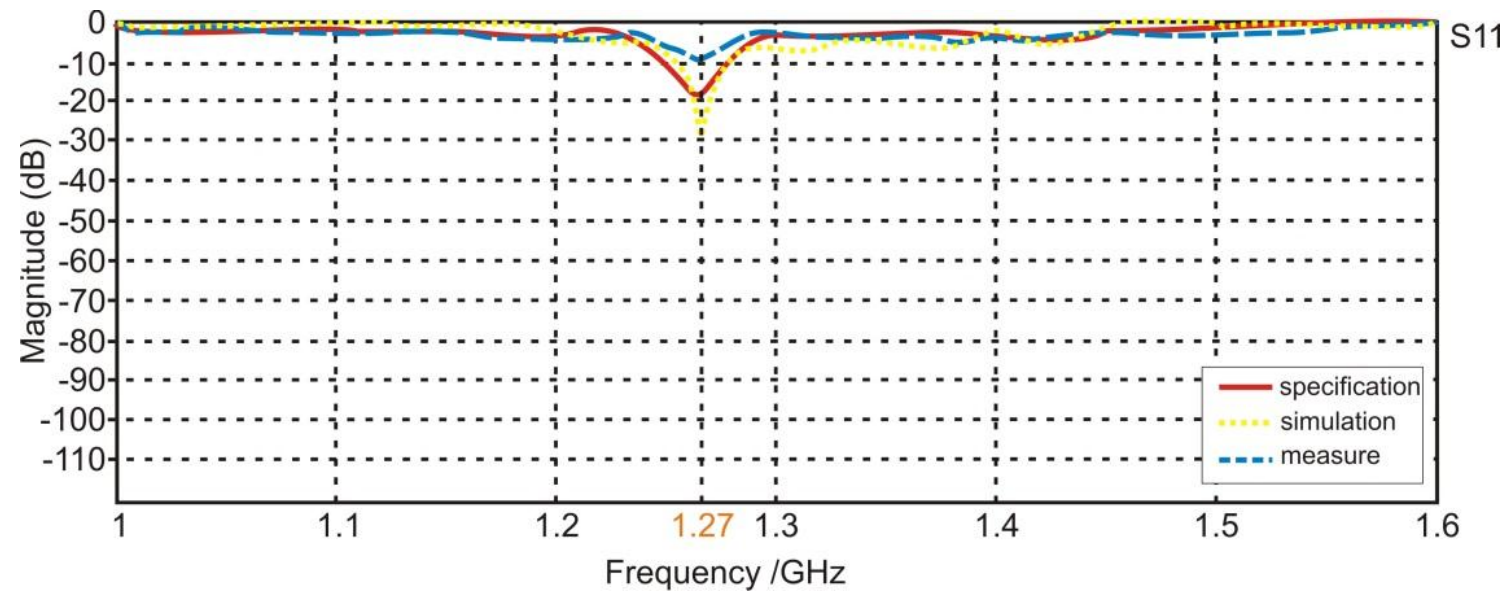

Gambar 17. Grafik Perbandingan pada spesifikasi, Simulasi dan Pengkuran

\subsubsection{Analisis Hasil Pengukuran Insertion Loss}

Berdasarkan hasil pengukuran Insertion Loss (S21), daerah passband mempunyai frekuensi $1252 \mathrm{MHz}$ sampai $1290 \mathrm{MHz}$. Kemudian nilai Insertion Loss pada frekunsi tengah $1270 \mathrm{MHz}$ berada pada level $-13.512 \mathrm{~dB}$. Karena nilai Insertion Loss sangat kecil maka daya output yang dihasilkan oleh filter Hairpin juga kecil, sehingga penggunaan daya pada filter ini tidak efisien. Padahal dalam kebutuhan Synthetic Aperture Radar kebutuhan penggunaan daya harus seefisien mungkin. Idealnya nilai Insertion Loss adalah sebesar $0 \mathrm{~dB}$ namun pada realisasinya sulit untuk dapat tercapai karena beberapa faktor yang mempengaruhi besarnya nilai Insertion Loss, diantaranya adalah Loss Dielektrik (rugi-rugi bahan), dan Loss Pabrikasi (proses etching dan penyolderan konektor).

\section{Loss Dielektrik}

Setiap bahan dielektrik memiliki rugi-rugi bahan (tan $\delta$ ) yang terakumulasi di setiap luas bahan. Nilai rugi-rugi bahan dielektrik dapat dihitung dengan persamaan (28) (Lancaster, 2001):

$$
\alpha_{d}=8.686 \pi\left(\frac{\varepsilon_{r e}-1}{\varepsilon_{r}-1}\right) \frac{\varepsilon_{r}}{\varepsilon_{r e}} \frac{\tan \delta}{\lambda_{\mathrm{g}}}
$$

Dengan $\tan \delta=0.02$ didapatkan redaman dielektrik sebesar $0.006078 \sim 0.0061 \mathrm{~dB} / \mathrm{cm}$. Dan untuk dimensi dielektrik dengn ukuran panjang $\times$ lebar $=13.5 \times 7.5 \mathrm{~cm}$ maka redaman 
dielektrik total dapat dihitung dengan mengkalikan nilai luas bahan dengan niai redaman dielektrik/satuan panjang. Kemudian didapatkan persamaan $13.5 \times 7.5 \times 0.02$ sehingga nilai redaman dielektrik total sebesar $0.62 \mathrm{~dB}$. Nilai redaman dielektrik total ini akan mengurangi fungsionalitas kerja filter Hairpin dengan menambah redaman sebesar $0.62 \mathrm{~dB}$.

\section{Loss Pabrikasi}

Loss pabrikasi diantaranya adalah ketidakpastian pada saat pencetakan jalur patch ke dalam papan PCB karena dalam pabrikasi filter mikrostrip selisih nilai sedikit saja sangat mempengaruhi hasil pengukuran. Loss pabrikasi juga timbul akibat penyolderan konektor yang kurang baik. Jika penyolderan konektor kurang baik akan mengakibatkan redaman filter semakin besar. Sehingga kedua hal tersebut harus sangat diperhatikan agar hasil pengukuran mendekati dengan nilai perancangan.

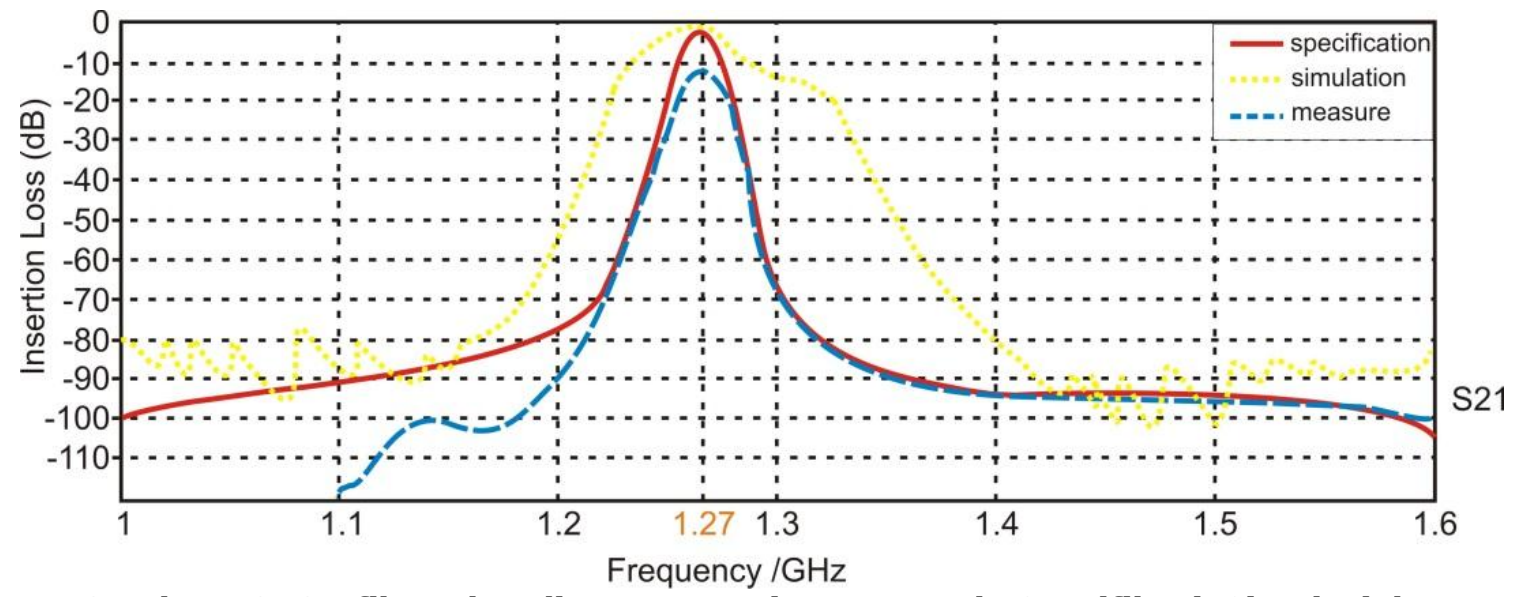

Gambar 18. Grafik Perbandingan Insertion Loss pada Spesifikasi, Simulasi dan Pengukuran

\subsubsection{Analisis Hasil Pengukuran Respon Fasa}

Respon fasa menunjukkan tingkat linieritas dari rangkaian yang memiliki daerah passband. Pada proses komunikasi, sinyal yang tidak linier akan mengakibatkan terjadinya delay. Berdasarkan hasil pengukuran, respon fasa filter Hairpin memiliki linieritas yang baik namun masih kurang akurat karena hasil nya dipengaruhi oleh nilai ripple yang dipakai dalam perancangan. Pada filter Hairpin ini karena dalam metode pembuatannya menggunakan respon chevbyshev yang memiliki selektivitas yang baik namun memiliki linieritas fasa yang kurang baik dengan nilai ripple $0.1 \mathrm{~dB}$.

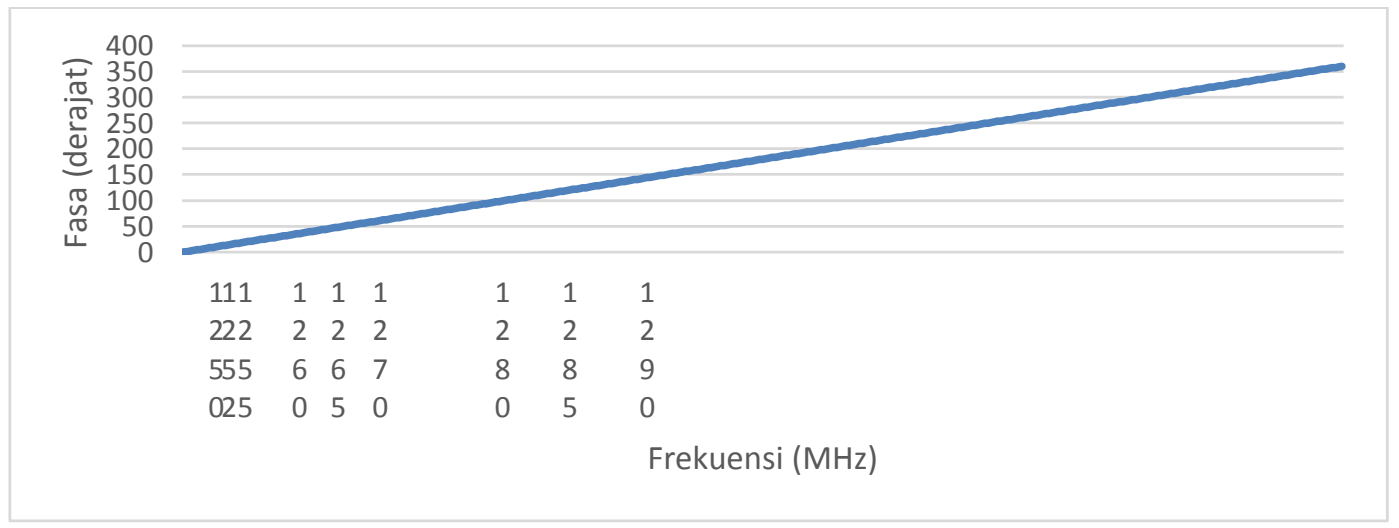

Gambar 19. Grafik Pengukuran Respon Fasa Passband 


\subsection{Analisis Kerja Sistem}

Analisis kerja sistem menunjukkan fungsional filter Hairpin hasil dari perancangan dengan membandingkan hasil pengukuran dengan spesifikasi awal yang direncanakan dan dari hasil simulasi. Berikut perbandingan spesifikasi awal, simulasi dan hasil pengukuran. Fungsionalitas filter Hairpin dalam melewatkan frekuensi yang aplikasinya terdapat dalam sistem Synthetic Aperture Radar dan meredam frekuensi lain yang tidak dibutuhkan oleh sistem karena dapat mengganggu kerja sistem.

Tabel 12. Perbadingan Spesifikasi, Hasil simulasi dan Hasil Pengukuran

\begin{tabular}{|l|l|l|l|}
\hline \multirow{2}{*}{\multicolumn{1}{c|}{ Parameter }} & \multicolumn{3}{c|}{ Daerah Passband } \\
\cline { 2 - 4 } & \multicolumn{1}{c|}{ Spesifikasi } & \multicolumn{1}{c|}{ Simulasi } & \multicolumn{1}{c|}{ Pengukuran } \\
\hline Range Frekuensi & $1265-1275 \mathrm{MHz}$ & $1265-1275 \mathrm{MHz}$ & $1252-1290 \mathrm{MHz}$ \\
\hline Bandwidth & $10 \mathrm{MHz}$ & $10 \mathrm{MHz}$ & $38 \mathrm{MHz}$ \\
\hline Frekuensi Tengah & $1270 \mathrm{MHz}$ & $1270 \mathrm{MHz}$ & $1270.625 \mathrm{MHz}$ \\
\hline Return LosS & $<-14 \mathrm{~dB}$ & $-40 \mathrm{~dB}$ & $-9.337 \mathrm{~dB}$ \\
\hline Insertion LosS & $-3 \mathrm{~dB}$ & $-7 \mathrm{~dB}$ & $-13.512 \mathrm{~dB}$ \\
\hline
\end{tabular}

Dari perbandingan hasil spesifikasi, simulasi dan hasil pengukuran di atas terdapat pergesaran range frekuensi dan bandwidth, pada hasil pengukuran menunjukkan lebih besar dbandingankan dengan spesifikasi dan hasil simulasi. Hal ini akan mempengaruhi kerja sistem Synthetic Aperture Radar yang seharusnya hanya mempunyai bandwidth sebesar 10 $\mathrm{MHz}$. Pada hasil pengukuran menunjukkan hasil $38 \mathrm{MHz}$, hal ini disebabkan karena ketidakakuratan software yang digunakan saat simulasi terhadap hasil pengukuran. Kemudian pada hasil pengukuran juga terlihat nilai Return Loss masih lebih besar jika dibandingkan dengan hasil perancangan, artinya masih bayak daya yang dipantulkan kembali ke sumber. Sehingga dalam penggunaan daya kurang efisien. Dan untuk Insertion Loss hasil pengukuran nilai nya masih terlalu kecil jika dibandingkan dengan hasil pengukuran, akibatnya di port output juga daya yang keluar akan kecil karena filter Hairpin ini bekerja saat nilai $-13.512 \mathrm{~dB}$ yang seharusnya nilai idealnya adalah $0 \mathrm{~dB}$.

Kemudian pada respon fasa, hasil ini akan berpengaruh terhadap nilai delay yang dapat mengganggu kerja sistem Synthetic Aperture Radar. Respon Chebyshev ini memiliki selektifitas yang baik, namun tingkat linieritas fasa tergantung pada nilai ripple yang dipakai pada perancangan yaitu sebesar $0.1 \mathrm{~dB}$.

\section{KESIMPULAN}

Setelah dilakukan pengukuran terhadap filter yang sudah dirancang, dapat diambil kesimpulan sebagai berikut:

1. Bandpass Filter berhasil direalisasikan menggunakan metode Hairpin-Line dengan elemen mikrostrip.

2. Proses perancangan Bandpass Filter menggunakan meetode Hairpin-Line berhasil disimulasikan menggunakan software CST Studio Suite 2010.

3. Bandpass Filter dapat melewatkan frekuensi yang dibutuhkan oleh sistem Synthetic Aperture Radar namun belum sesuai dengan spesifikasi awal pada perancangan. Nilai bandwidth yang dihasilkan masih terlalu lebar yaitu $38 \mathrm{MHz}$.

4. Bandpass Filter dapat meredam sumber interferensi di luar range frekuensi namun belum sesuai dengan spesifikasi awal pada perancangan. 
5. Return Loss yang dihasilkan oleh Bandpass Filter dengan metode Hairpin-Line pada daerah passband adalah $-9.337 \mathrm{~dB}$.

6. Insertion Loss yang dihasilkan oleh Bandpass Filter dengan metode Hairpin-Line pada daerah passband adalah $-13.512 \mathrm{~dB}$.

7. Respon fasa Bandpass Filter pada daerah passband menunjukkan respon yang linier.

\section{DAFTAR RUJUKAN}

Budi Syihabuddin, D. A. (2017). Perancangan Bandpass Filter Pita Sempit pada Frekuensi LBand untuk Aplikasi Synthetic Aperture Radar (SAR). JURNAL INFOTEL.

Edwar, M. A. ( 2016). Microstrip BPF made of square loop resonator for X-band weather radar. 2nd International Conference on Wireless and Telematics (ICWT) (pp. 10 - 13). IEEE.

J. T. Sri Sumantyo, H. W. (2009). Development of Circularly Polarized Synthetic Aperture Radar Onboard Microsatellite ( $\mu S A T$ CP-SAR). PIERS Proceedings. Beijing China.

Jiejin Wu, W. C. (2008). Design of band-pass Filters at Ka-band with waveguide to microstrip transition. 8th International Symposium on Antennas, Propagation and EM Theory. Kunming, China: IEEE.

Lancaster, J.-S. H. (2001). Microstrip Filters for RF/Microwave Applications : John Wiley \& Sons, Inc.

Pozar, D. M. (1998). Microwave Engineering Second Edition : John Wiley \& Sons ,Inc.

Rustamaji, A. R. (2013). Simulasi Perancangan Filter Analog dengan Respon Chebyshev. Jurnal Elkomika, 1(2): 106-116.

Sulaeman, E., Darlis, A.R. \& Dewi, R.H.A. (2013). Perancangan dan Implementasi Duplexer Mikrostrip untuk Frekuensi LTE pada band ke-7. Jurnal Elkomika, 1(2): 68-78.

T.Jayanthy, K. a. (2011). Design of Microstrip Hairpin BAnd Pass Filter Using Ground Structure and Open Stubs. International Conference on Information and Electronics Engineering.

Zalabsky, T. (2013). Design and Modeling of an Output Microwave Filter for S Band Primary Radar Transmitter. 13th Conference on Microwave Techniques COMITE 2013. Pardubice, Czech Republic: IEEE. 